\title{
1 Thyroid cancer incidence and mortality in Latin America
}

2

3 Fábia Cheyenne Gomes de Morais Fernandes, MSc

4 Dyego Leandro Bezerra de Souza ${ }^{2 *}, \mathrm{PhD}$

5 Maria Paula Curado 3 , $\mathrm{PhD}$

6 Isabelle Ribeiro Barbosa ${ }^{1}, \mathrm{PhD}$

7

$8{ }^{1}$ Faculty of Health Sciences of Trairi (FACISA), Federal University of Rio Grande do Norte,

$9 \quad$ Natal, Rio Grande do Norte, Brazil;

${ }^{2}$ Graduate Program in Collective Health, Federal University of Rio Grande do Norte, Natal,

11 Rio Grande do Norte, Brazil;

$12{ }^{3}$ Epidemiology Departament, International Center for Research AC Camargo Center - São 13 Paulo-SP, Brazil.

*Corresponding author: Dyego Leandro Bezerra de Souza: dysouz@yahoo.com.br

CurrentAddress: Universidade Federal do Rio Grande do Norte / Federal University of Rio

Grande do Norte. Programa de Pós-Graduação em Saúde Coletiva / Graduate Program in

Collective Health. Avenida Senador Salgado Filho 1787, CEP: 59010-000 Lagoa Nova,

Natal-RN, Brazil. Telephone/fax: +55 84 3215-4133.

Financing: This work was financed in part by the Coordenação de Aperfeiçoamento de Pessoal de Nível Superior - Brazil (CAPES) - financing code 001, and by the Conselho Nacional de Desenvolvimento Científico e Tecnológico (CNPq), in the modality PIBIC CNPq. 


\section{ABSTRACT}

This study analyzed trends in thyroid cancer incidence and mortality in countries of Latin America. Ecological study of time series, with incidence data extracted from the International Agency for Research on Cancer (IARC), in the 1990-2012 period and mortality data obtained from 16 countries of the World Health Organization (WHO), in the 1995-2013 period. The trend of incidence rate was analyzed by the Joinpoint regression. The average annual percentage change (AAPC) and the 95\% confidence interval (CI 95\%) were calculated for incidence and mortality. The average rate of thyroid cancer incidence was higher in Quito (Ecuador) between the ages of 40 to 59 years old, 42.2 new cases per 100,000 inhabitants, as well as mortality 4.8 deaths per 100,000 women inhabitants above 60 years old. There was an increase in thyroid cancer incidence trends in women, for all age groups, in Cali, Costa Rica and Quito and men in Costa Rica; there was stability above the age of 60 years old in Cali, Goiania, Quito and Valdivia in men, as well as women in Goiania and Valdivia. There was a trend of increasing mortality for females in three countries: Ecuador (AAPC $=3,28 \mathrm{CI} 95 \%$ 1,36;5,24), Guatemala (AAPC $=6,14 \mathrm{CI} 95 \%$ 2,81;9,58) and Mexico (AAPC $=0,67 \mathrm{CI} 95 \%$ $0,16 ; 1,18)$. Thyroid cancer in Latin America showed a high incidence, with increased incidence in women. Stability in mortality was observed for most countries of Latin America.

Keywords: Thyroid Neoplasms; Trends; Incidence; Mortality; Latin America. 
67

\section{INTRODUCTION}

The thyroid malignancy neoplasm represents approximately $2 \%$ of all cancers in the world (1). In 2016, were estimated 238,000 new cases of thyroid cancer and 43.000 deaths for both sexes in the world, with a standardized incidence rate of 2.2/100,000 for male inhabitants and 4.4/100.000 for female inhabitants female (2). The incidence rate in Northern Americans exceeds most European countries $(3,4)$.

In South America, in 2012, the incidence rate for thyroid cancer was 8.4 cases/100.00 women and 1.9/100,000 men (1). It was classified between the fifth to the tenth most common type of cancer among women and the 25th most commonly diagnosed cancer in men in Central and South America (5). There is an increased tendency to the female incidence in Brazil, Colombia, Costa Rica, and Ecuador, as the males in Brazil and Costa Rica (6). High income countries show a substantial increase in the incidence (7), considered to be two times higher compared to low/medium income countries, for both sexes (8).

Thyroid cancer is considered rare, but in the last 30 a sharp increase in incidence was registered, attributed to higher diagnostic intensity, although environmental influences, genetic and dietary merit further investigation $(9,10)$. This cancer is characterized with predominance in females, white race and the median age of 45 years, but with a tendency to increase among young adults $(9,11,12)$.

Latin America faces difficulties to fulfill an agenda of continuous commitments, with appropriate financial incentives and effective approaches to cancer control. Therefore it becomes relevant to describe the epidemiological profile of thyroid cancer in these countries. The aim of this study was analyze the incidence, mortality, rates, and trends for thyroid cancer in Latin America.

\section{METHODS}

This is about an ecological time series study, based on secondary data available in the databases of the International Agency for Research on Cancer (IARC) and the World Health Organization (WHO) $(13,14)$. Occurrence and mortality for malignant thyroid neoplasm were analyzed in Latin American countries.

Incident cases of thyroid malignancy, during the period of 22 years (1990-2012), were extracted from the Cancer Incidence in Five Continents - CI5 PLUS, which includes five Population Based Cancer Registries (PBCRs): four regional registries, Cali (Colombia), Quito 
100 (Ecuador), Goiania (Brazil) and Valdivia (Chile) and one national record, Costa Rica (13).

101 The mortality data, for which the available information was analyzed of 16 countries of Latin

102

103

104

105

106

107

108

109

110

111

112

113

114

115

116

117

118

119

120

121

122

123

124 America, accounted for $90 \%$ of the population in Latin America between 1995 to 2013 (14).

The number of cases was extracted and adjusted rate-specific by age and calculated for three age groups (25-39, 40-59, and 60-74) and for all ages. Specific rates, adjusted by age, were calculated using the standard world population, according to sex and countries with available data.

The incidence rates and standardized mortality rates were calculated by sex. Also were calculated the Ratio of incidence and mortality rates by sex. The average annual percentage change (AAPC) was estimated for incidence and mortality with a 95\% confidence interval (CI 95\%) in the period. The exception to these analyses were Suriname and Uruguay, due to the lack of cases in the historical series. The statistical analyses were performed using the software Joinpoint Regression, version 4.5.0.0 (15,16).

\section{RESULTS}

Between 1990 and 2012, the higher incidence rates of thyroid cancer were observed in Quito (Ecuador) and Costa Rica, in females, aged 40 to 59 years, with rates of 41.2/100,000 to 28.0/100,000, respectively. For males, the highest rates were observed in Quito (Ecuador) and Cali (Colombia), over 60 years, $11.7 / 100,000$ to $7.3 / 100,000$, respectively. (Table 1, Figure 1).

Table 1. Age standardized incidence rate (ASIR), number of cases $(N)$, average annual percent change (AAPC), and incidence rate ratio (SIR) for thyroid cancer, according to age and sex, in Cali (Colombia), Costa Rica, Goiania (Brazil), Quito (Ecuador) and Valdivia (Chile), for the period 1990-2012.

\begin{tabular}{|c|c|c|c|c|c|c|c|}
\hline \multirow[b]{2}{*}{$\begin{array}{l}\text { Population Based } \\
\text { Cancer Registries }\end{array}$} & \multirow[b]{2}{*}{ Data } & \multirow[b]{2}{*}{ Age } & \multicolumn{2}{|c|}{ Male } & \multicolumn{2}{|c|}{ Female } & \multirow[b]{2}{*}{ SRI } \\
\hline & & & $\operatorname{ASIR}(N)$ & $\begin{array}{c}\text { AAPC } \\
\left(\text { IC } 95 \%{ }^{1}\right)\end{array}$ & $\begin{array}{l}\text { ASIR } \\
(N)\end{array}$ & $\begin{array}{c}\text { AAPC } \\
\left(\text { IC } 95 \%^{1}\right)\end{array}$ & \\
\hline \multirow[t]{4}{*}{ Cali (Colombia) } & $\begin{array}{l}1990- \\
2012\end{array}$ & $25-39$ & $1.7(88)$ & $4.5(1.6 ; 7.5)$ & $\begin{array}{c}9.5 \\
(541)\end{array}$ & $4.2(2.8 ; 5.7)$ & 0.17 \\
\hline & & $40-59$ & $4.9(190)$ & $7.7(3.7 ; 11.9)$ & $\begin{array}{c}22.5 \\
(1051)\end{array}$ & $5.1(4.0 ; 6.3)$ & 0.21 \\
\hline & & $60-74$ & $7.3(91)$ & $1.3(-2.3 ; 4.9)$ & $\begin{array}{l}27.7 \\
(447)\end{array}$ & $4.5(2.8 ; 6.3)$ & 0.26 \\
\hline & & Total & $4.1(369)$ & $4.7(2.8 ; 6.7)$ & 18.2 & $4.7(3.8 ; 5.6)$ & 0.22 \\
\hline
\end{tabular}




\begin{tabular}{|c|c|c|c|c|c|c|c|}
\hline & & & & & (2039) & & \\
\hline \multirow[t]{4}{*}{ Costa Rica } & $\begin{array}{l}1990- \\
2012\end{array}$ & $25-39$ & $1.9(193)$ & $7.3(4.5 ; 10.3)$ & $\begin{array}{c}13.2 \\
(1320)\end{array}$ & $6.4(5.1 ; 7.6)$ & 0.14 \\
\hline & & $40-59$ & $4.5(358)$ & $5.3(3.6 ; 7.0)$ & $\begin{array}{c}28.0 \\
(2225)\end{array}$ & $7.8(6.1 ; 9.6)$ & 0.16 \\
\hline & & $60-74$ & $4.9(117)$ & $7.5(5.5 ; 9.7)$ & $\begin{array}{c}20.9 \\
(533)\end{array}$ & $6.4(4.8 ; 8.1)$ & 0.23 \\
\hline & & Total & $3.5(668)$ & $6.5(5.3 ; 7.6)$ & $\begin{array}{c}20.8 \\
(4078)\end{array}$ & $7.3(6.4 ; 8.3)$ & 0.16 \\
\hline \multirow[t]{4}{*}{ Goiania (Brazil) } & $\begin{array}{l}1993- \\
2012\end{array}$ & $25-39$ & $3.1(87)$ & $4.1(-0.6 ; 9.1)$ & $\begin{array}{c}11.5 \\
(369)\end{array}$ & $8.9(5.7 ; 12.3)$ & 0.26 \\
\hline & & $40-59$ & $4.0(82)$ & $5.0(1.2 ; 8.9)$ & $\begin{array}{c}22.7 \\
(547)\end{array}$ & $8.7(6.1 ; 11.4)$ & 0.17 \\
\hline & & $60-74$ & $6.3(36)$ & $-1.9(-4.9 ; 1.2)$ & $\begin{array}{c}25.6 \\
(188)\end{array}$ & $3.3(-0.2 ; 7.1)$ & 0.24 \\
\hline & & Total & $4.0(205)$ & $4.5(2.3 ; 6.8)$ & $\begin{array}{c}18.7 \\
(1104)\end{array}$ & $7.9(5.1 ; 10.8)$ & 0.21 \\
\hline \multirow[t]{4}{*}{ Quito (Ecuador) } & $\begin{array}{l}1990- \\
2012\end{array}$ & $25-39$ & $2.9(107)$ & $7.0(4.0 ; 10.0)$ & $\begin{array}{c}18.0 \\
(746)\end{array}$ & $6.2(3.6 ; 8.9)$ & 0.16 \\
\hline & & $40-59$ & $6.7(173)$ & $11.7(7.8 ; 15.9)$ & $\begin{array}{c}41.2 \\
(1225)\end{array}$ & $9.9(6.6 ; 13.3)$ & 0.16 \\
\hline & & $60-74$ & $11.7(97)$ & $0.6(-3.4 ; 4.7)$ & $\begin{array}{c}39.6 \\
(396)\end{array}$ & $7.6(5.9 ; 9.4)$ & 0.29 \\
\hline & & Total & $6.1(377)$ & $7.3(4.2 ; 10.4)$ & $\begin{array}{c}31.6 \\
(2367)\end{array}$ & $8.3(6.2 ; 10.4)$ & 0.19 \\
\hline \multirow[t]{4}{*}{ Valdívia (Chile) } & $\begin{array}{l}1998- \\
2012\end{array}$ & $25-39$ & $1.2(7)$ & $1.0(-0.2 ; 2.2)$ & $9.4(58)$ & $\begin{array}{c}12.1(4.6 \\
20.1)\end{array}$ & 0.12 \\
\hline & & $40-59$ & $2.1(14)$ & $7.1(2.7 ; 11.7)$ & $\begin{array}{l}11.8 \\
(76)\end{array}$ & $8.6(-0.3 ; 18.4)$ & 0.17 \\
\hline & & $60-74$ & $6.1(15)$ & $-3.9(-9.1 ; 1.7)$ & $\begin{array}{l}12.9 \\
(35)\end{array}$ & $\begin{array}{c}1.8(-14.0 \\
20.5)\end{array}$ & 0.47 \\
\hline & & Total & $2.5(36)$ & $1.2(-7.4 ; 10.6)$ & $\begin{array}{c}11.0 \\
(169)\end{array}$ & $7.0(3.1 ; 11.0)$ & 0.22 \\
\hline
\end{tabular}

Increasing incidence trends for thyroid cancer were evident in both sexes and all age 128 groups, with the exception of the males, of Group 60 to 74 years in Cali (Colombia) $1.3 \%$ 129 [95\% CI:-2.3; 4.9]; Goiania (Brazil), between 25-39 years [4.1\%; CI 95\%: -0.6; 9.1] and 130 between 60-74 years old [-1,9\%; CI 95\%: -4,9; 1,2]; Quito (Ecuador), between 60-74 years 131 [0.6\%; CI 95\%:-3.4; 4.7]; Valdivia (Chile), between 25-39 years [1.0\%; CI 95\%:-0.2; 2.2) and 
132 between $60-74$ years [-3.9\%; CI 95\%:-9.1; 1.7]. For females, there was stability in the age 133 group between 60-74 years in Goiania (Brazil), [3.3\%; CI 95\%:-0.2; -7.1) and Valdivia 134 (Chile), between 40-59 years [8.6\%; CI 95\%:-0.3; 18.4] and between 60-74 years [1.8\%; CI $13595 \%:-14.0 ; 20.5]$. The incidence trends by age group followed similar patterns in Cali 136 (Colombia), Costa Rica, Goiania (Brazil), Quito (Ecuador) and Valdivia (Chile), with the 137 highest increase trends for women (Table 1, Figures 1, 2 and 3.).

138 Between 1995 and 2013, the highest rates of thyroid cancer mortality were observed in 139 Ecuador, in the age group 60-74 years (2.2/100,000 in men and 4.8/100,000 women). 140 According to the ratio of the rates (ASMR), mortality was higher in women in most countries 141 but presented Ratio equal to 1 in Ecuador between 25-39 years and Uruguay in groups of 2514239 years and 40-59 years (Table 2).

144 Table 2. Age standardized mortality rate (ASMR) per 100,000, number $(N)$ of deaths and 145 mortality rate ratio (SMR) for thyroid cancer, by sex and age-group, for 17 Latin American 146 populations, in the period 1995-2013.

\begin{tabular}{|c|c|c|c|c|c|}
\hline \multirow[b]{2}{*}{ Population } & \multirow[b]{2}{*}{ Data } & \multirow[b]{2}{*}{ Age } & \multicolumn{2}{|c|}{$\operatorname{ASMR}(N)$} & \multirow[b]{2}{*}{ SRM } \\
\hline & & & Male & Female & \\
\hline \multirow[t]{4}{*}{ Argentina } & $1997-2013$ & $25-39$ & $0.0(25)$ & $0.1(45)$ & 0.0 \\
\hline & & $40-59$ & $0.3(238)$ & $0.4(317)$ & 0.75 \\
\hline & & $60-74$ & $1.5(437)$ & $2.0(755)$ & 0.75 \\
\hline & & Total & $0.4(700)$ & $0.6(1117)$ & 0.66 \\
\hline \multirow[t]{4}{*}{ Brazil } & $1996-2013$ & $25-39$ & $0.0(126)$ & $0.0(166)$ & 0.0 \\
\hline & & $40-59$ & $0.3(810)$ & $0.4(1278)$ & 0.75 \\
\hline & & $60-74$ & $1.2(1211)$ & $1.9(2440)$ & 0.63 \\
\hline & & Total & $0.3(2147)$ & $0.5(3884)$ & 0.6 \\
\hline \multirow[t]{4}{*}{ Chile } & $1997-2013$ & $25-39$ & $0.0(12)$ & $0.0(14)$ & 0.0 \\
\hline & & $40-59$ & $0.4(119)$ & $0.5(154)$ & 0.8 \\
\hline & & $60-74$ & 1.7 (194) & $3.0(405)$ & 0.56 \\
\hline & & Total & $0.5(325)$ & 0.7 (573) & 0.71 \\
\hline \multirow[t]{4}{*}{ Colombia } & $1997-2013$ & $25-39$ & $0.0(38)$ & $0.1(66)$ & 0.0 \\
\hline & & $40-59$ & $0.3(235)$ & 0.7 (495) & 0.42 \\
\hline & & $60-74$ & $2.0(411)$ & 3.9 (952) & 0.51 \\
\hline & & Total & $0.5(684)$ & $1.0(1513)$ & 0.5 \\
\hline
\end{tabular}




\begin{tabular}{|c|c|c|c|c|c|}
\hline \multirow[t]{4}{*}{ Costa Rica } & 1997-2013 & $25-39$ & $0.0(2)$ & $0.1(5)$ & 0.0 \\
\hline & & $40-59$ & $0.3(21)$ & $0.4(27)$ & 0.75 \\
\hline & & $60-74$ & $1.2(31)$ & $2.6(70)$ & 0.46 \\
\hline & & Total & $0.3(54)$ & $0.6(102)$ & 0.5 \\
\hline \multirow[t]{4}{*}{ Ecuador } & $1997-2013$ & $25-39$ & $0.1(21)$ & $0.1(23)$ & 1.0 \\
\hline & & $40-59$ & $0.4(78)$ & $0.9(184)$ & 0.44 \\
\hline & & $60-74$ & $2.2(144)$ & $4.8(355)$ & 0.45 \\
\hline & & Total & $0.6(243)$ & $1.3(562)$ & 0.46 \\
\hline \multirow[t]{4}{*}{ El Salvador } & $1997-2013$ & $25-39$ & $0.0(1)$ & $0.0(5)$ & 0.0 \\
\hline & & $40-59$ & $0.2(15)$ & $0.4(39)$ & 0.50 \\
\hline & & $60-74$ & $1.2(39)$ & $2.0(79)$ & 0.6 \\
\hline & & Total & $0.3(55)$ & $0.5(123)$ & 0.6 \\
\hline \multirow[t]{4}{*}{ Guatemala } & $2000-2013$ & $25-39$ & $0.0(5)$ & $0.1(13)$ & 0.0 \\
\hline & & $40-59$ & $0.3(29)$ & $0.6(79)$ & 0.50 \\
\hline & & $60-74$ & $0.9(40)$ & $2.0(97)$ & 0.45 \\
\hline & & Total & $0.3(74)$ & $0.6(189)$ & 0.5 \\
\hline \multirow[t]{4}{*}{ México } & $1998-2013$ & $25-39$ & $0.0(99)$ & $0.1(141)$ & 0.0 \\
\hline & & $40-59$ & $0.4(587)$ & $0.8(1181)$ & 0.5 \\
\hline & & $60-74$ & $2.1(1015)$ & $4.0(2180)$ & 0.52 \\
\hline & & Total & $0.6(1701)$ & $1.1(3502)$ & 0.54 \\
\hline \multirow[t]{4}{*}{ Nicarágua } & $1997-2013$ & $25-39$ & $0.0(2)$ & $0.1(6)$ & 0.0 \\
\hline & & $40-59$ & $0.4(21)$ & $0.5(36)$ & 0.80 \\
\hline & & $60-74$ & $1.3(25)$ & $3.1(71)$ & 0.41 \\
\hline & & Total & $0.4(48)$ & $0.8(113)$ & 0.5 \\
\hline \multirow[t]{4}{*}{ Panamá } & $1998-2013$ & $25-39$ & $0.1(5)$ & $0.0(3)$ & 0.0 \\
\hline & & $40-59$ & $0.3(16)$ & $0.5(25)$ & 0.60 \\
\hline & & $60-74$ & $1.9(32)$ & $2.6(48)$ & 0.73 \\
\hline & & Total & $0.5(53)$ & $0.7(76)$ & 0.71 \\
\hline \multirow[t]{4}{*}{ Paraguai } & 1996-2013 & $25-39$ & $0.0(5)$ & $0.0(3)$ & 0.0 \\
\hline & & $40-59$ & $0.5(43)$ & $0.6(49)$ & 0.83 \\
\hline & & $60-74$ & $2.1(57)$ & $3.2(91)$ & 0.65 \\
\hline & & Total & $0.6(105)$ & $0.8(143)$ & 0.75 \\
\hline \multirow[t]{3}{*}{ Peru } & 1999-2013 & $25-39$ & $0.0(23)$ & $0.1(36)$ & 0.0 \\
\hline & & $40-59$ & $0.4(126)$ & $0.7(271)$ & 0.57 \\
\hline & & $60-74$ & $1.7(214)$ & 3.7 (509) & 0.45 \\
\hline
\end{tabular}




\begin{tabular}{|c|c|c|c|c|c|}
\hline & & Total & $0.5(363)$ & $1.0(816)$ & 0.5 \\
\hline \multirow[t]{4}{*}{ Suriname } & $1995-2013$ & $25-39$ & - & - & - \\
\hline & & $40-59$ & - & $0.2(2)$ & - \\
\hline & & $60-74$ & $0.7(2)$ & $2.3(8)$ & 0.3 \\
\hline & & Total & $0.1(2)$ & $0.5(10)$ & 0.2 \\
\hline \multirow[t]{4}{*}{ Uruguai } & $1997-2010$ & $25-39$ & $0.1(3)$ & $0.1(3)$ & 1.0 \\
\hline & & $40-59$ & $0.5(24)$ & $0.5(25)$ & 1.0 \\
\hline & & $60-74$ & $1.5(38)$ & $2.3(75)$ & 0.65 \\
\hline & & Total & $0.5(65)$ & $0.6(103)$ & 0.83 \\
\hline \multirow[t]{4}{*}{ Venezuela } & $1996-2013$ & $25-39$ & $0.0(20)$ & $0.1(32)$ & 0.0 \\
\hline & & $40-59$ & $0.4(154)$ & $0.6(245)$ & 0.66 \\
\hline & & $60-74$ & $1.6(207)$ & $2.8(405)$ & 0.57 \\
\hline & & Total & $0.5(381)$ & $0.8(682)$ & 0.62 \\
\hline
\end{tabular}

There was no homogeneous pattern in trends of mortality in the 16 countries studied 151 (Figure 4). In the age group 60-74 years, for women, it was observed an increase in 152 Guatemala and reduction in Brazil. For men, the eleven countries that had historical series 153 showed a trend of stability (Argentina, Brazil, Chile, Colombia, Ecuador, El Salvador, 154 Guatemala, Mexico, Peru, Uruguay,and Venezuela). There was reduction in male mortality rate in Brazil, aged 40-59 years (-1.23\%; CI 95\%:-2.42; -0.02), while in female, the highest increase was observed in Guatemala (8.77\%; CI 95\%: 3.06-14.81), for all ages (Table 3).

Table 3. Thyroid cancer mortality trends, by sex and age-group for 17 Latin American populations, in theperiod 1995-2013.

\begin{tabular}{ccccc}
\hline \multirow{2}{*}{ Population } & \multirow{2}{*}{ Data } & Age & \multicolumn{2}{c}{ AAPC (95\% CI) } \\
\cline { 4 - 5 } & & & Male & Female \\
\hline Argentina & $1997-2013$ & & - & - \\
& & $40-59$ & $-1.11(-4.18 ; 2.07)$ & $0.52(-1.81 ; 2.90)$ \\
& $60-74$ & $0.70(-2.03 ; 3.51)$ & $-1.06(-2.73 ; 0.64)$ \\
& & $0.26(-1.70 ; 2.26)$ & $-0.62(-1.88 ; 0.66)$ \\
Brazil & Total & $0.29(-3.79 ; 4.55)$ & $0.86(-3.51 ; 5.44)$ \\
& \multirow{2}{*}{$1996-2013$} & $25-39$ & $-1.23(-2.42 ;-0.02)$ & $-0.76(-1.69 ; 0.18)$ \\
& & $40-59$ & $-0.37(-1.63 ; 0.90)$ & $-1.46(-2.33 ;-0.59)$
\end{tabular}




\begin{tabular}{|c|c|c|c|c|}
\hline & & Total & $-0.62(-1.48 ; 0.24)$ & $-1.15(-1.81 ;-0.49)$ \\
\hline \multirow[t]{4}{*}{ Chile } & $1997-2013$ & $25-39$ & - & - \\
\hline & & $40-59$ & $-3.14(-7.18 ; 1.09)$ & $-1.42(-4.98 ; 2.27)$ \\
\hline & & $60-74$ & $-1.00(-3.99 ; 2.09)$ & $-0.91(-2.50 ; 0.71)$ \\
\hline & & Total & $-1.95(-4.01 ; 0.16)$ & $-0.97(-2.43 ; 0.50)$ \\
\hline \multirow[t]{4}{*}{ Colombia } & $1997-2013$ & $25-39$ & - & - \\
\hline & & $40-59$ & $-0.26(-3.00 ; 2.56)$ & $0.52(-1.60 ; 2.67)$ \\
\hline & & $60-74$ & $-0.94(-3.02 ; 1.19)$ & $0.11(-1.38 ; 1.61)$ \\
\hline & & Total & $-0.84(-2.27 ; 0.62)$ & $0.35(-0.92 ; 1.63)$ \\
\hline \multirow[t]{4}{*}{ Costa Rica } & $1997-2013$ & $25-39$ & - & - \\
\hline & & $40-59$ & - & - \\
\hline & & $60-74$ & - & $-2.94(-7.48 ; 1.82)$ \\
\hline & & Total & - & $-1.72(-6.04 ; 2.80)$ \\
\hline \multirow[t]{4}{*}{ Equador } & $1997-2013$ & $25-39$ & - & - \\
\hline & & $40-59$ & $-0.13(-4.84 ; 4.81)$ & $2.11(-2.23 ; 6.65)$ \\
\hline & & $60-74$ & $0.75(-2.92 ; 4.57)$ & $2.01(-0.88 ; 4.98)$ \\
\hline & & Total & $0.49(-2.38 ; 3.45)$ & $1.83(-0.33 ; 4.03)$ \\
\hline \multirow[t]{4}{*}{ El Salvador } & 1997-2013 & $25-39$ & - & - \\
\hline & & $40-59$ & - & - \\
\hline & & $60-74$ & $1.47(-3.79 ; 7.03)$ & $-0.76(-4.86 ; 3.51)$ \\
\hline & & Total & $-1.20(-5.59 ; 3.39)$ & $1.89(-2.44 ; 6.41)$ \\
\hline \multirow[t]{4}{*}{ Guatemala } & $2000-2013$ & $25-39$ & - & - \\
\hline & & $40-59$ & - & - \\
\hline & & $60-74$ & $6.75(-1.07 ; 15.18)$ & $8.37(2.02 ; 15.13)$ \\
\hline & & Total & $5.74(-0.69 ; 12.58)$ & $8.77(3.06 ; 14.81)$ \\
\hline \multirow[t]{4}{*}{ Mexico } & $1998-2013$ & $25-39$ & $3.60(-2.68 ; 10.29)$ & $2.73(-0.91 ; 6.51)$ \\
\hline & & $40-59$ & $0.75(-1.58 ; 3.14)$ & $0.63(-0.48 ; 1.74)$ \\
\hline & & $60-74$ & $0.68(-0.86 ; 2.24)$ & $0.68(-0.05 ; 1.41)$ \\
\hline & & Total & $0.71(-0.30 ; 1.74)$ & $0.73(0.20 ; 1.27)$ \\
\hline \multirow[t]{4}{*}{ Nicaragua } & 1997-2013 & $25-39$ & - & - \\
\hline & & $40-59$ & - & - \\
\hline & & $60-74$ & - & - \\
\hline & & Total & - & $4.07(0.07 ; 8.24)$ \\
\hline \multirow[t]{2}{*}{ Panama } & 1998-2013 & $25-39$ & - & - \\
\hline & & $40-59$ & - & - \\
\hline
\end{tabular}




\begin{tabular}{|c|c|c|c|c|}
\hline & & $60-74$ & - & - \\
\hline & & Total & - & $-0.20(-4.40 ; 4.18)$ \\
\hline \multirow[t]{4}{*}{ Paraguai } & $1996-2013$ & $25-39$ & - & - \\
\hline & & $40-59$ & - & - \\
\hline & & $60-74$ & - & - \\
\hline & & Total & - & $1.82(-1.95 ; 5.73)$ \\
\hline \multirow[t]{4}{*}{ Peru } & 1999-2013 & $25-39$ & - & - \\
\hline & & $40-59$ & $3.87(-3.58 ; 11.89)$ & $-2.17(-4.52 ; 0.23)$ \\
\hline & & $60-74$ & $0.49(-3.45 ; 4.60)$ & $0.56(-1.03 ; 2.18)$ \\
\hline & & Total & $1.51(-1.83 ; 4.97)$ & $-0.33(-1.39 ; 0.74)$ \\
\hline \multirow[t]{4}{*}{ Uruguai } & $1997-2010$ & $25-39$ & - & - \\
\hline & & $40-59$ & - & - \\
\hline & & $60-74$ & $-1.36(-5.12 ; 2.55)$ & $-0.22(-6.42 ; 6.38)$ \\
\hline & & Total & $-0.82(-7.24 ; 6.04)$ & $-1.86(-7.70 ; 4.35)$ \\
\hline \multirow[t]{4}{*}{ Venezuela } & $1996-2013$ & $25-39$ & - & - \\
\hline & & $40-59$ & $-1.06(-3.55 ; 1.49)$ & $0.06(-1.51 ; 1.66)$ \\
\hline & & $60-74$ & $0.52(-1.79 ; 2.88)$ & $1.12(-0.47 ; 2.74)$ \\
\hline & & Total & $-0.07(-1.77 ; 1.66)$ & $0.66(-0.35 ; 1.69)$ \\
\hline
\end{tabular}

DISCUSSION

The incidence of thyroid cancer occurred more frequently in the age group of 40 to 59 years in Costa Rica and Quito (Ecuador), while in Cali (Colombia), Goiania (Brazil) and Valdivia (Chile) there was a higher incidence in the age group over 60 years. The highest rates were observed in women, found similar to other studies $(8,17)$. observed in Cali, Goiania, Quito and Valdivia for men in the age group above 60 years. The increase in incidence trends, for both sexes, is also observed in developed and developing countries, such as Denmark (male: AAPC $=3.2 \%$; $<<0.05$ and female: AAPC $=3.6 \%$; $<<$ 0.05 ); United States (male: AAPC $=3.1 \%$; CI 95\%: 2.7-3.5 and female: $\mathrm{AAPC}=3.7 \%$; CI 95\%: 3.3-4.1) and China with AAPC $=22.86 \%$ (CI 95\%: 19.2-26.7), similar to both sexes (1820).

The main risk factor associated with thyroid cancer is ionizing radiation because this gland is radiosensitive in young age and is in a position that allows for greater uptake of radiation. This increased incidence may be related to increased individual radiation dose 
observed in recent decades, through medical and dental diagnostic procedures, which has greater impact when exposure occurs during childhood $(21,22)$.

The factors that contribute to the temporal trends and geographic variations include the prevalence of obesity and diabetes among the countries $(23,24)$. It can be verified that in Latin America and the Caribbean, 16\% of men and 20\% of women were obese (25). Another factor is the enrichment of iodine in the diet, whose risk for thyroid cancer may differ based on the availability of iodine, is excess or scarcity $(3,26)$. By analyzing the incidence of thyroid cancer in São Paulo (Brazil) and the United States it was found that the differences in the nutritional status of iodine among populations may have affected the observed incidence patterns (27).

Other possible risk factors associated with women are sex hormones in interaction with the Thyroid-Stimulating Hormone (TSH), which can play a critical role in the development of thyroid malignancy, as well as advanced age in menopause and the greater parity $(28,29)$. In men, it was found a positive association with the story of goiter, thyroid nodules and family history of cancer (30). However, the consumption of tobacco and alcohol were not associated with increased risk $(31,32)$.

However, authors discuss whether there is a real increase of thyroid cancer or dealing with an epidemic of diagnoses, due to the heterogeneous pattern between a rising incidence and mortality rates $(10,33)$. This increased incidence is assigned to detection of subclinical disease and non-lethal, for better access to the health system, incidental detection of the image and more frequent biopsy $(34,35)$. Sierra et al. (5) showed that the increased incidence of thyroid cancer in Argentina, Brazil, Chile and Costa Rica was driven primarily by the increased incidence of papillary subtype.

The distinctive thyroid cancer, follicular and papillary subtypes, which represents the highest percentage of all thyroid cancers and is responsible for the increasing incidence of the disease, presents very good prognosis and low mortality (36). The estimated survival rate of 5 years for thyroid cancer is excellent when identified. The age has a strong effect on the disease-specific survival because it decreases with the increasing of age. Furthermore, males were associated with a significantly worse survival rate among patients with regional disease (37).

In most of the countries of Latin America there was stability in the mortality trend. Corroborating with the finds in China, there was stability in mortality from thyroid cancer $(\mathrm{AAPC}=2.05 \%$; CI 95\%:-1.7-6.0), for both sexes, and Central Serbia, male AAPC $=2.4 \%$ (CI 95\%: -0.5-5.5) and female AAPC $=-1.3 \%$ (CI 95\%: -4.4-1.9) (19, 38). In the United States, 
in the 1994-2013 period, the mortality increased $0.9 \%$ per year (CI 95\%: $0.7-1.5$ ), for both sexes (20).

Only Argentina, Brazil, Chile, Cuba and Nicaragua in Latin America are implementing policies, strategies or action plans specifically for cancer. Countries such as Belize, Ecuador, Mexico, Nicaragua and Panama are advancing in this regard, while several countries in the region have an absence (or lack) of relevant information that would make possible their monitoring strategies for cancer control (39).

In regard to the quality of the data, the absence of population-based registers with historical series made it impossible for the inclusion of other data. To mortality, differences were found in the comprehensiveness and completeness of the 17 countries studied, ranging from 55\% in the Dominican Republic completeness and 90\% in Argentina, Chile, Costa Rica, Mexico, Uruguayand Venezuela. In addition, the percentage of ill-defined deaths ranged from 5\% (Costa Rica and Mexico) to 24\% (El Salvador) (40). Despite these limitations, the data have been validated by international organizations and can be used to describe the mortality in Latin American countries (41-43).

This study analyzed the incidence of thyroid cancer in four cities and one country of Latin America (Costa Rica) and the mortality trends for thyroid cancer in 16 countries of Latin America. Both incidences as mortality showed differences, with an increase in women of Cali (Colombia), Costa Rica, Goiania (Brazil) and Quito (Ecuador). There was stability in mortality trends in most countries of Latin America.

Figure 1. Thyroid cancer age-adjusted incidence rates (95\% confidence interval) for sex, age range 25-39 and 40-59 years, for Cali (Colombia), Costa Rica, Goiania (Brazil), Quito (Ecuador) and Valdivia (Chile), for the period 1990-2012. 95\% CI: 95\% confidence interval. The grayline represents trends over the period.

Figure 2. Thyroid cancer age-adjusted incidence rates (95\% confidence interval), by sex, age 60-74 years and total, for Cali (Colombia), Costa Rica, Goiania (Brazil), Quito (Ecuador) and Valdivia (Chile), for the period 1990-2012. 95\% CI: 95\% confidence interval. The grayline represents trends over the period.

Figure 3. Temporal trends in thyroid cancer mortality, according to sex, and age 60-74 years, in 16 Latin American countries, for the period 1995-2013. (A) Female; (B) Male. 


\section{AUTHOR CONTRIBUTIONS}

248 Conceptualization: DS MC IR.

249 Data curation: FF IR.

250 Formal analysis: FF IR.

251 Funding acquisition: FF IR.

252 Investigation: FF DS MC IR.

253 Methodology: DS MC IR.

254 Project administration: IR.

255 Resources: FF DS MC IR.

256 Software: DS MC IR.

257 Supervision: DS IR.

258 Validation: DS MC IR.

259 Visualization: FF DS MC IR.

260 Writing \pm original draft: FF.

261 Writing \pm review \& editing: FF DS MC IR.

262

263

264

265

266

\section{REFERENCES}

1. Ferlay J, Soerjomataram I, Dikshit R, Eser S, Mathers C, Rebelo M, et al. Cancer incidence and mortality worldwide: Sources, methods and major patterns in Globocan 2012. Int J Cancer. 2015; 136: E359-E386. doi: 10.1002/ijc.29210.

2. Global Burden of Disease Cancer Collaboration. Global, Regional, and National Cancer Incidence, Mortality, Years of Life Lost, Years Lived With Disability, and Disability-Adjusted Life-Years for 29 Cancer Groups, 1990 to 2016: A Systematic Analysis for the Global Burden of Disease Study. JAMA Oncology. 2018. doi: 10.1001/jamaoncol.2018.2706. 
3. Vigneri R, Malandrino P, Vigneri P. The changing epidemiology of thyroid cancer: why is incidence increasing? Curr Opin Oncol. 2015;27:1-7. DOI: 10.1097/CCO.0000000000000148.

4. Ferlay J, Steliarova-Foucher E, Lortet-Tieulent J, Rosso S, Coebergh JWW, Comber H, Bray F. Cancer incidence and mortality patterns in Europe: estimates for 40 countries in 2012. European journal of cancer. 2013;49(6):1374-1403.

5. Sierra MS, Soerjomataram I, Forman D. Thyroid cancer burden in Central and South America. Cancer Epidemiology. 2016;44S:S150-S157. Doi: http://dx.doi.org/10.1016/j.canep.2016.07.017.

6. Borges AKM, Miranda-Filho A, Koifmam S, Koifman RJ. Thyroid Cancer Incidences From Selected South America Population-Based Cancer Registries: An Age-PeriodCohort Study. J GlobOncol. 2017. DOI: https://doi.org/10.1200/JGO.17.00024.

7. Vaccarella S, Maso LD, Laversanne M, Bray F, Plummer M, Franceschi S. The Impact of Diagnostic Changes on the Rise in Thyroid Cancer Incidence: A PopulationBased Study in Selected High-Resource Countries. Thyroid. 2015;25. https://doi.org/10.1089/thy.2015.0116.

8. Vecchia CL et al. Thyroid cancer mortality and incidence: A global overview.Int. J. Cancer. 2014;136:2187-2195. DOI: 10.1002/ijc.29251.

9. Vergamini LB, Frazier AL, Abrantes FL, Ribeiro KB, Rodriguez-Galindo C. Increase in the Incidence of Differentiated Thyroid Carcinoma in Children, Adolescents, and Young Adults: A Population-Based Study. J Pediatr. 2014;164:1481-5. http://dx.doi.org/10.1016/j.jpeds.2014.01.059.

10. Kitahara CM, Sosa JA. The changing incidence of thyroid cancer. Nature. 2016; 12. doi: 10.1038/nrendo.2016.110.

11. Adam MA, Thomas S, Hyslop T, Scheri RP, Roman SA, Sosa JA. Exploring the Relationship Between Patient Age and Cancer-Specific Survival in Papillary Thyroid Cancer: Rethinking Current Staging Systems. J ClinOncol. 2016; 34: 4415-4420. doi: 10.1200/JCO.2016.68.9372.

12. Lewis DR et al. Early Estimates of Cancer Incidence for 2015: Expanding to Include Estimates for White and Black Races. Cancer. 2018. DOI: 10.1002/cncr.31315.

13. Ferlay J, Bray F, Steliarova-Foucher E, Forman D. Cancer incidence in five continents, CI5plus. IARC Cancer Base; 2014. 
14. World Health Organization (WHO) Databank. Health statistics and information systems. Geneva, Switzerland: WHO. Available at http://www.who.int/healthinfo/ statistics/mortalityrawdata/en/ (accessed May 2018).

15. Program JR. Version 4.5.0.0 ed: Statistical methodology and applications branch, Surveillance Research Program, National Cancer Institute.

16. Kim HJ, Fay MP, Feuer EJ, Midthune DN. Permutation tests for joinpoint regression with applications to cancer rates. Stat Med. 2000;19:335-351.

17. Meza R, Chang JT Multistage carcinogenesis and the incidence of thyroid cancer in the US by sex, race, stage and histology. BMC Public Health. 2015;15:789. DOI: 10.1186/s12889-015-2108-4.

18. Mirian C, Grønhøj C, Jensen DH, Jakobsen KK, Karnov K, Jensen JS et al. Trends in thyroid cancer: Retrospective analysis of incidence and survival in Denmark 19802014. Cancer Epidemiology. 2018;55:81-7. https://doi.org/10.1016/j.canep.2018.05.009.

19. Du L, Wang Y, Sun X, Li H, Geng X, Ge M, Zhu Y. Thyroid cancer: trends in incidence, mortality and clinical-pathological patterns in Zhejiang Province, Southeast China. BMC Cancer. 2018;18:291. https://doi.org/10.1186/s12885-018-4081-7.

20. Lim H, Devesa SS, Sosa JA, Check D, Kitahara CM. Trends in Thyroid Cancer Incidence and Mortality in the United States, 1974-2013. JAMA. 2017; 317(13):1338-1348. DOI: 10.1001/jama.2017.2719.

21. Pellegriti G, Frasca F, Regalbuto C, Squatrito S, Vigneri R. Worldwide Increasing Incidence of Thyroid Cancer: Update on Epidemiology and Risk Factors. J CancerEpidemiol. 2013. http://dx.doi.org/10.1155/2013/965212.

22. Mitsutake N, Fukushima T, Matsuse M, Rogounovitch T, Saenko V, Uchino S et al. BRAFV600E mutation is highly prevalent in thyroid carcinomas in the young population in Fukushima: a different oncogenic profile from Chernobyl. Nature. 2015;5(16976). DOI: 10.1038/srep16976.

23. Li H, Quian J. Association of diabetes mellitus with thyroid cancer risk: A meta$\begin{array}{llll}\text { analysis of cohort } \quad \text { studies. Medicine. } & \text { 2017;96:47. }\end{array}$ http://dx.doi.org/10.1097/MD.0000000000008230.

24. Marcello MA, Cunha LL, Batista FA, Ward LS. Obesity and thyroid câncer. Endocrine-Related Cancer. 2014;21:255-271. DOI: 10.1530/ERC-14-0070.

25. Kelly T, Yang W, Chen C-S, Reynolds K, He J. Global burden of obesity in 2005 and projections to 2030. International Journal of Obesity. 2008;32:1431-1437. 
26. Cho YA, Kim J. Dietary Factors Affecting Thyroid Cancer Risk: A Meta-Analysis. Nutr Cancer. 2015;67(5):811-7. DOI: 10.1080/01635581.2015.1040517.

27. Veiga LHS, Gila Neta, Aschebrook-Kilfoy B, Ron E, Devesa SS. Thyroid Cancer Incidence Patterns in Sao Paulo, Brazil, and the U.S. SEER Program, 1997-2008. Thyroid. 2013;23(6):748-757. DOI: 10.1089/thy.2012.0532.

28. Cao Y, Wang Z, Gu J, Hu F, Qi Y, Yin Q, Sun Q, Li G, Quan B. Reproductive Factors but Not Hormonal Factors Associated with Thyroid Cancer Risk: A Systematic Review and Meta-Analysis. BioMed Research International. 2015. http://dx.doi.org/10.1155/2015/103515.

29. Zhu J et al. Parity and thyroid cancer risk: a meta-analysis of epidemiological studies. Cancer Medicine. 2016;5(4):739-752. DOI: 10.1002/cam4.604.

30. Zivaljevic V, Slijepcevic N, Sipetic S, Paunovic I, Diklic A, Zoric G et al. Risk factors for well-differentiated thyroid cancer in men. Tumori. 2013;99:456-460. DOI: $10.1700 / 1361.15094$.

31. Sadeghi H, Rafei M, Bahrami M, Haghdoost A, Shabani Y. Attributable risk fraction of four lifestyle risk factors of thyroid cancer: a meta-analysis. J Public Health (Oxf). 2017;9:1-8. DOI: 10.1093/pubmed/fdx088.

32. Hong S-H, Myung S-K, Kim HS. Alcohol Intake and Risk of Thyroid Cancer: A Meta-Analysis of Observational Studies. Cancer Res Treat. 2017;49(2):534-547. https://doi.org/10.4143/crt.2016.161.

33. Vecchia CL, Negri E. The thyroid cancer epidemic -overdiagnosis or a real increase? Nature. 2017. DOI: 10.1038/nrendo.2017.53.

34. Davies L et al. American Association of Clinical Endocrinologists and American College of Endocrinology Disease State Clinical Review: The Increasing Incidence of Thyroid Cancer. Endocr Pract. 2015;21(6):686-696. DOI: 10.4158/EP14466.DSCR.

35. Nagar S, Aschebrook-Kilfoy $\quad$ B, Kaplan $\quad$ EL, Angelos $\quad$ P, Grogan $\quad$ RH. Age of diagnosing physician impacts the incidence of thyroid cancer in a population. Cancer Causes Control. 2014;25(12):1627-34. DOI: 10.1007/s10552-014-0467-2.

36. Roman BR, Morris LG, Davies L. The thyroid cancer epidemic, 2017 perspective. Curr Opin Endocrinol Diabetes Obes 2017, 24:332-336. DOI: 10.1097/MED.0000000000000359.

37. Banerjee M, Muenz DG, Worden FP, Wong SL, Haymart MR. Conditional Survival in Patients with Thyroid Cancer. Thyroid. 2014;24(12). DOI: 10.1089/thy.2014.0264 
38. Stojanovic M, Stojanovic D, Ranc`ic N, Ignjatovic A, Antic Z, Miljkovic S, Rajovic T. Trends in thyroid cancer incidence and mortality in Central Serbia,1999-2014. Ann Ist Super Sanita. 2017:53(4):299-304. DOI: 10.4415/ANN_17_04_05.

39. Forman D, Sierra MS. Cancer in Central and South America: Introduction. Cancer Epidemiology. 2016; S3-S10. http://dx.doi.org/10.1016/j.canep.2016.04.008.

40. World Health Organization (WHO) Databank. Health statistics and information systems. Geneva, Wwitzerland: WHO Available at http://www.who.int/healthinfo/statistics/mortalityrawdata/en/ (accessed July 2018).

41. Ferlay J, Soerjomataram I, Dikshit R, Eser S, Mathers C, Rebelo M, et al. Cancer incidence and mortality worldwide: sources, methods and major patterns in GLOBOCAN 2012. Int. J. Cancer. 2015;136: E359-E386.

42. Curado M P, Edwards B, Shin HR, Storm H, Ferlay J, Heanue M, et al. Cancer incidence in five continents Vol. IX. IARC Press, Lyon, France. 2007.

43. Forman D, Bray F, Brewster D, Gombe Mbalawa C, Kohler B, Piñeros M, et al. Cancer incidence in Five continents Vol. X. IARC, Lyon. 2013. 
Male (Cali, Colombia)

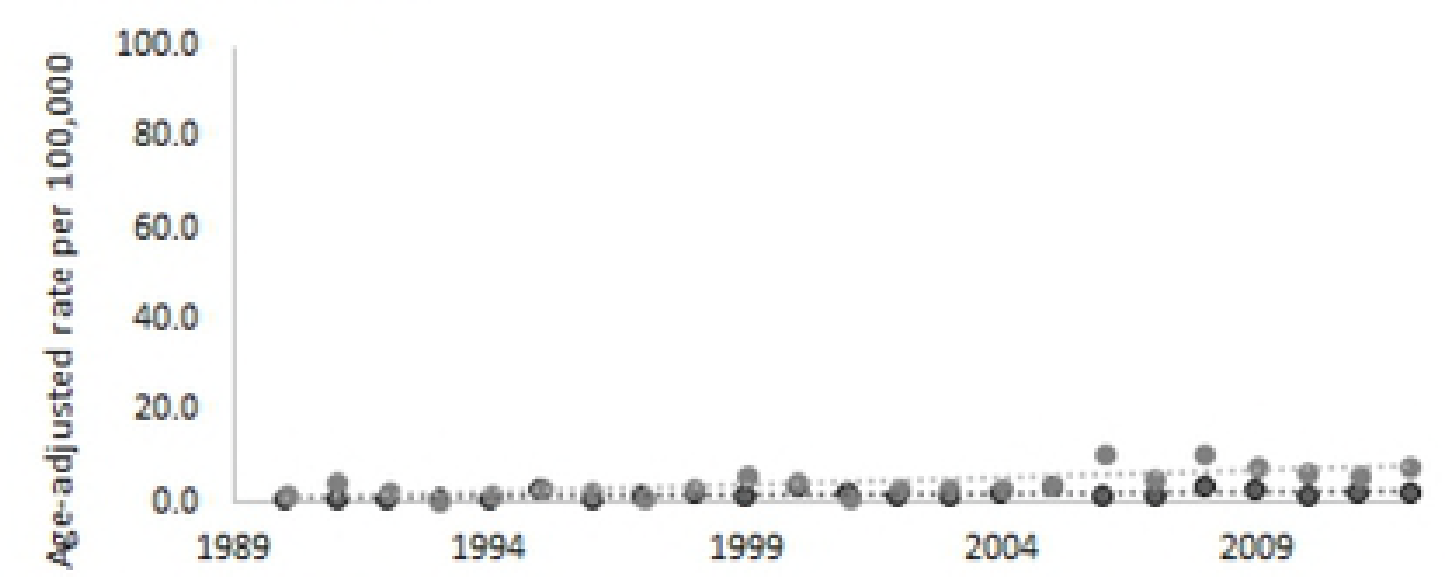

- Standardized incidence rate 25-39 years …...... Incidence trend $25-39$ years - Standardized incidence rate 40.59 years ……. Incidence trend 40.59 years

Male (Costa Rica)

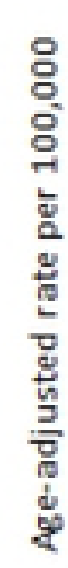

80.0
60.0
40.0
20.0

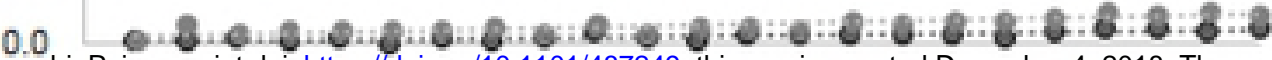

bioRxiv preprint di: Hups.

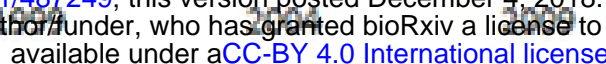

- Standardized incidence rate 25-39 years - Incidence trend $25-39$ years

- Standardized incidence rate 40-59 years ......... Incidence trend 40.59 years

Male (Goiania, Brazil)

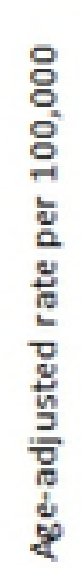

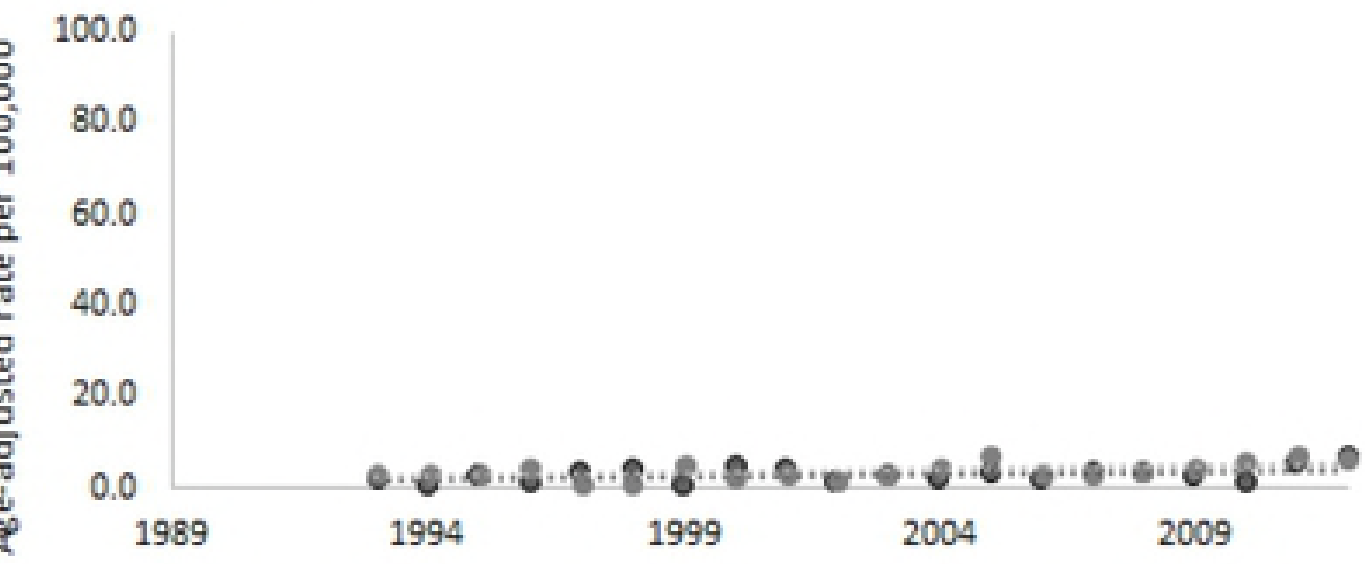

- Standardized incidence rate $25-39$ years Incidence trend $25-39$ years

- Standardized incidence rate 40-59 years

Male (Quito, Ecuador)

.

80.0

60.0

40.0

20.0

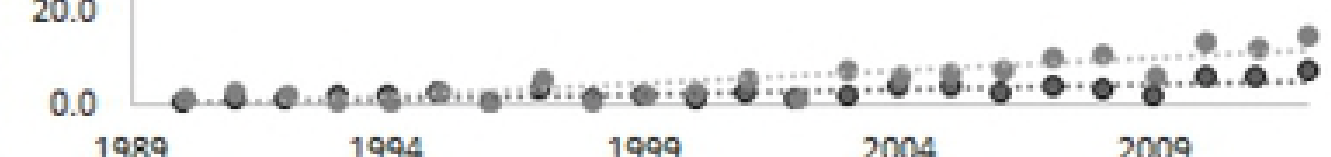

- Standardized incidence rate $25-39$ years

- Standardized incidence rate $40-59$ years

Incidence trend 25-39 years

Male (Valdivia, Chile)

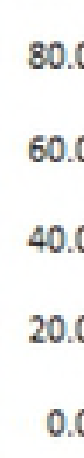

30.0

60.0

40.0

20.0

0.0 1989 1994

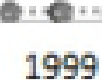

2004

2009

- Standardized incidence rate 25-39 years

Incidence trend $25-39$ years

Standardized incidence rate 40-59 years

Incidence trend $40-59$ years
Female (Cali, Colombia)

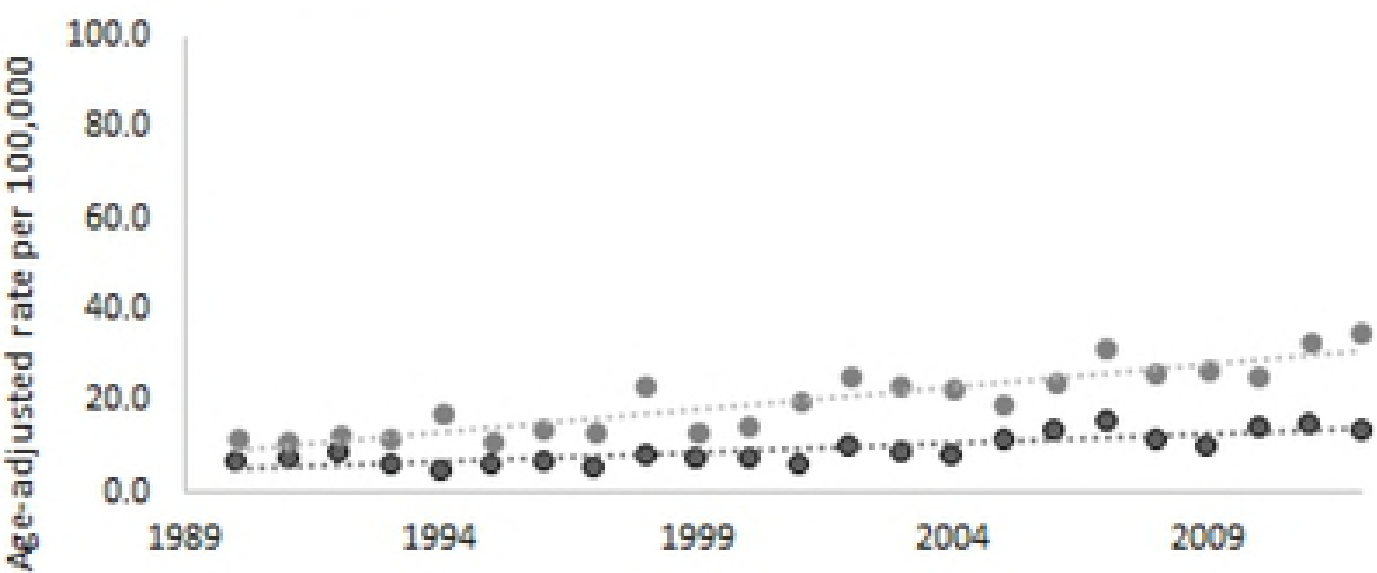

- Standardized incidence rate 25-39 years

Incidence trend $25-39$ years

Standardized incidence rate $40-59$ years ncidence trend 40.59 years Female (Costa Rica)

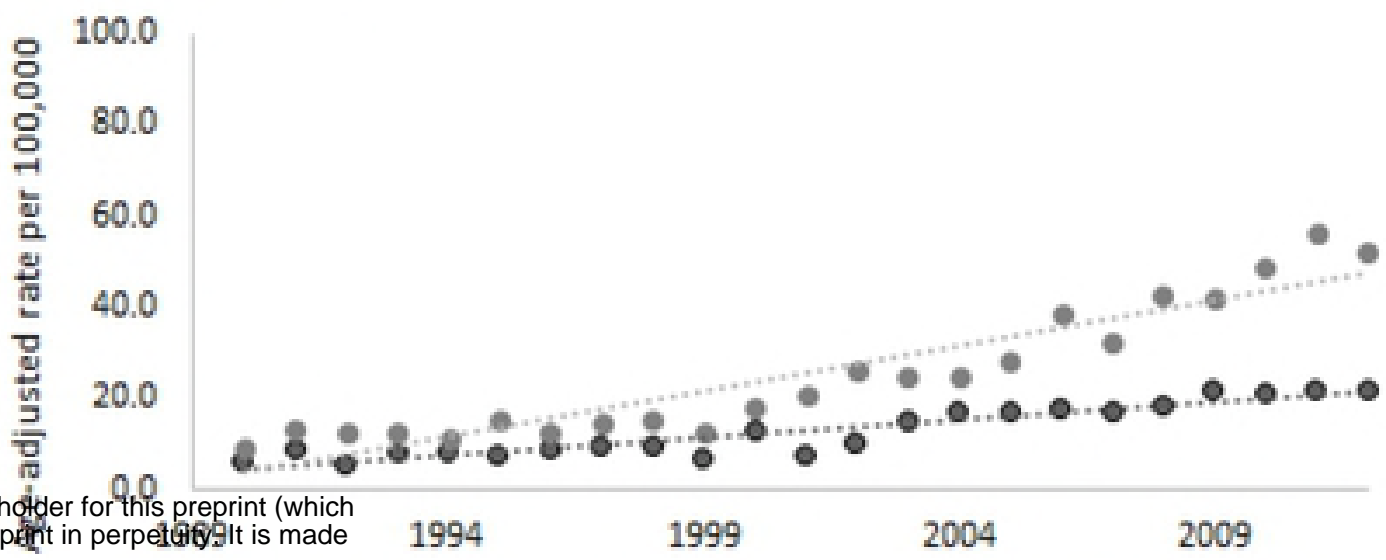

- Standardized incidence rate $25-39$ years

Incidence trend $25-39$ years - Standardized incidence rate 40-59 years Incidence trend $40-59$ years Female (Goiania, Brazil)

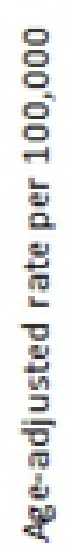

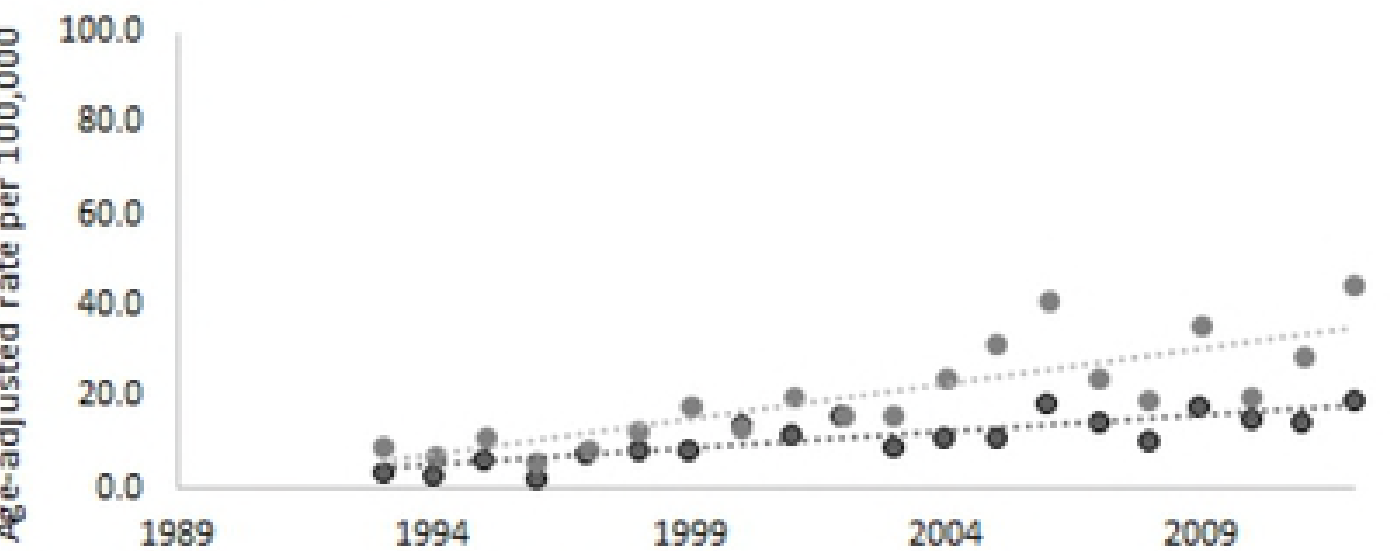

- Standardized incidence rate 25-39 years …...... Incidence trend $25-39$ years

- Standardized incidence rate $40-59$ years ......... Incidence trend $40-59$ years Female (Quito, Ecuador)

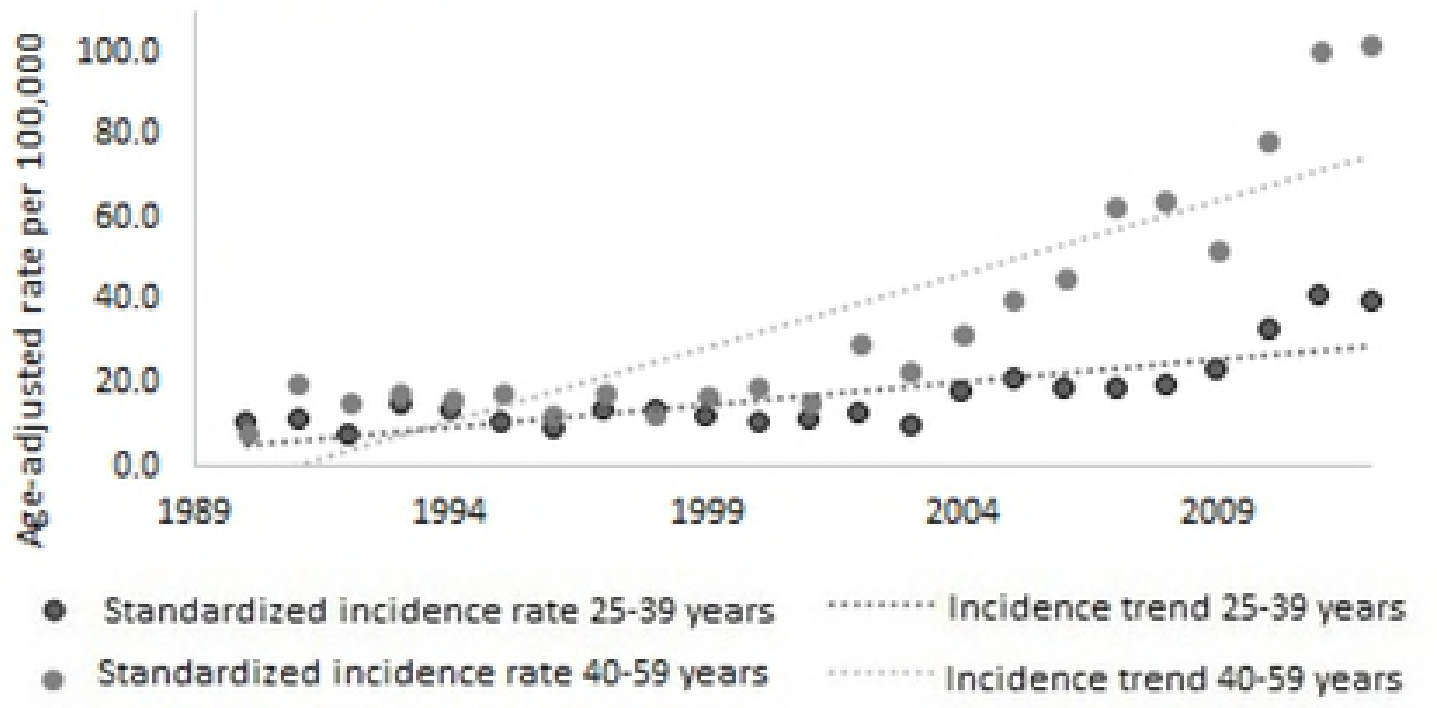

Female (Valdivia, Chile)

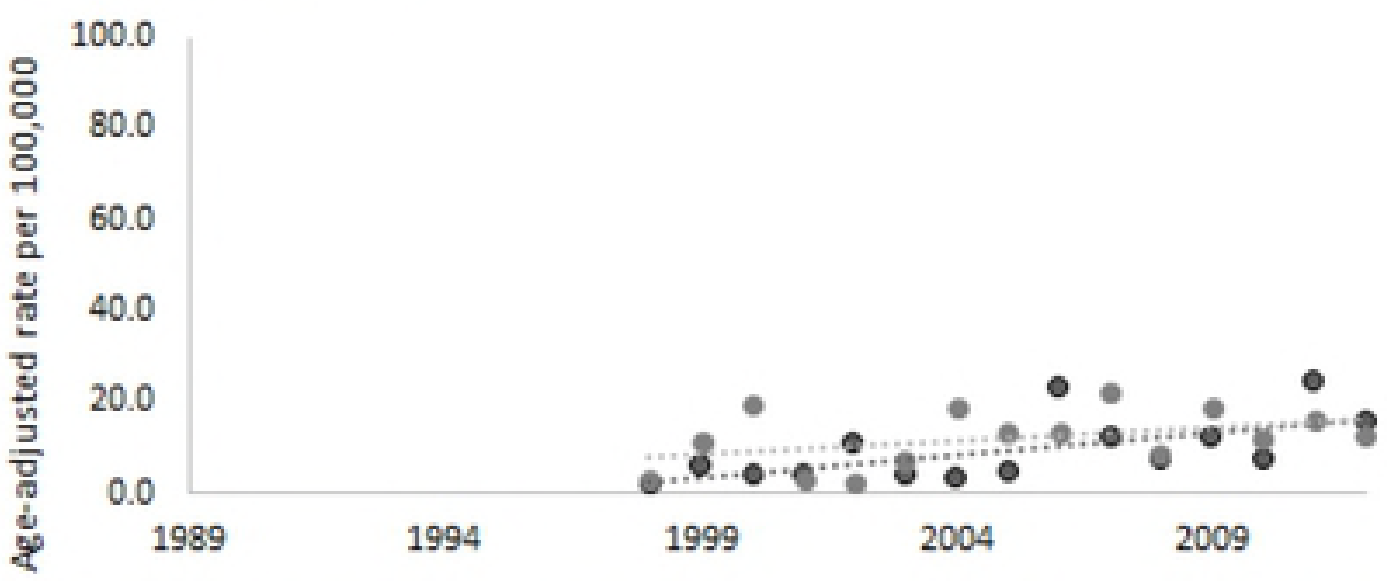

- Standardized incidence rate $25-39$ years …..... Incidence trend $25-39$ years - Standardized incidence rate 40-59 years .......... Incidence trend $40-59$ years

Figure 1 
Male (Cali, Colombia)

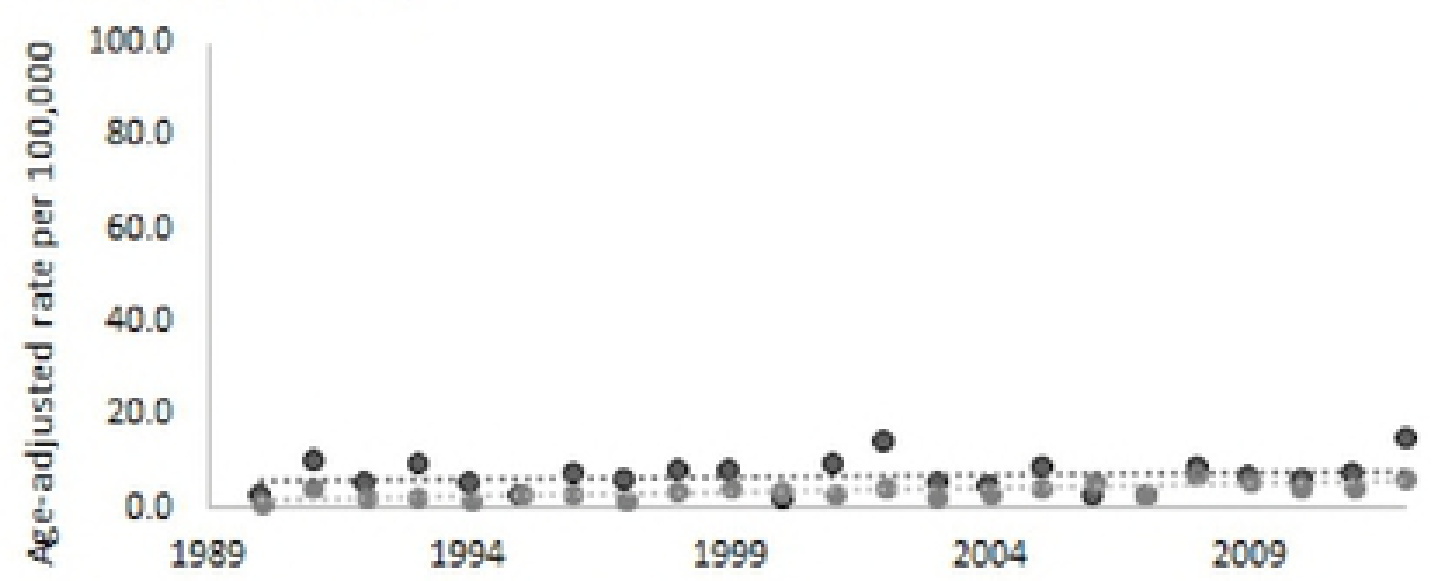

- Standardized incidence rate $60-74$ years $\quad \cdots . . . . . .$. Incidence trend 60.74 years

- Standardized incidence rate Total $\quad$........... Incidence trend Total

Male (Costa Rica)

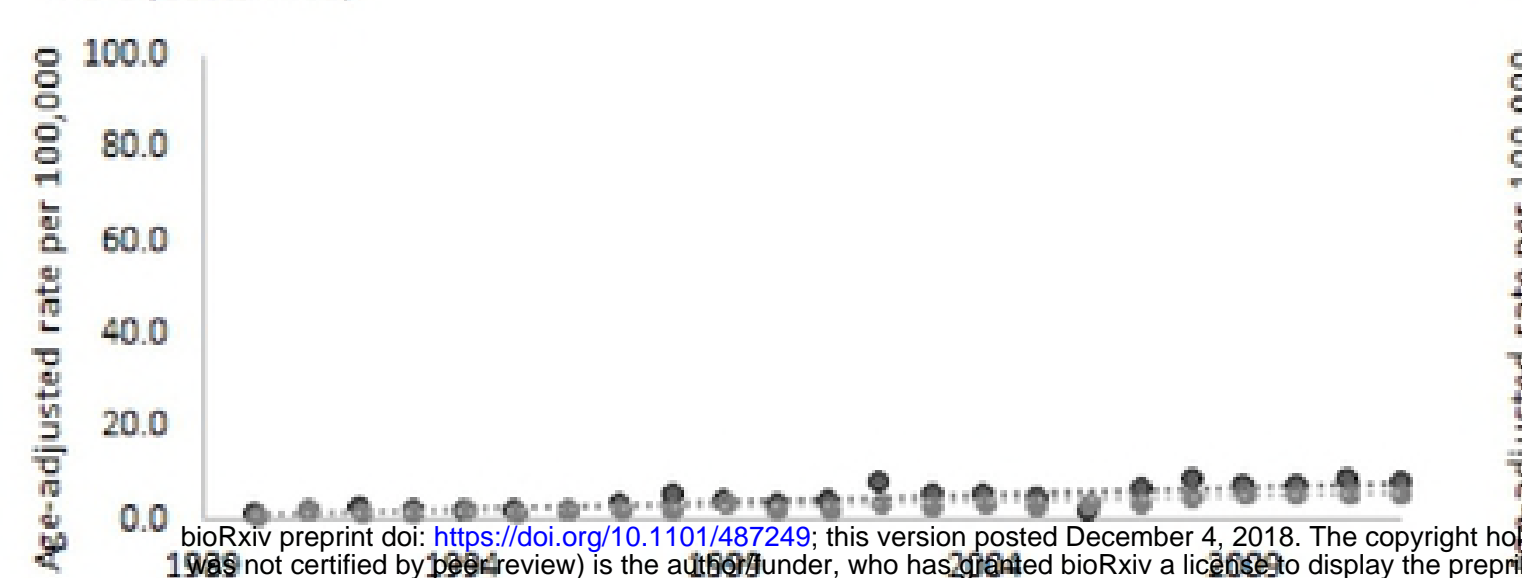

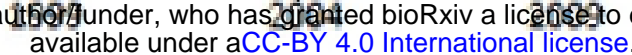

- Standardized incidence rate 60-74 years …....... Incidence trend $60-74$ years

- Standardized incidence rate Total

.......... Incidence trend Total

Male (Goiania, Brazil)

8
8
0
0
0
$\vdots$
$\vdots$

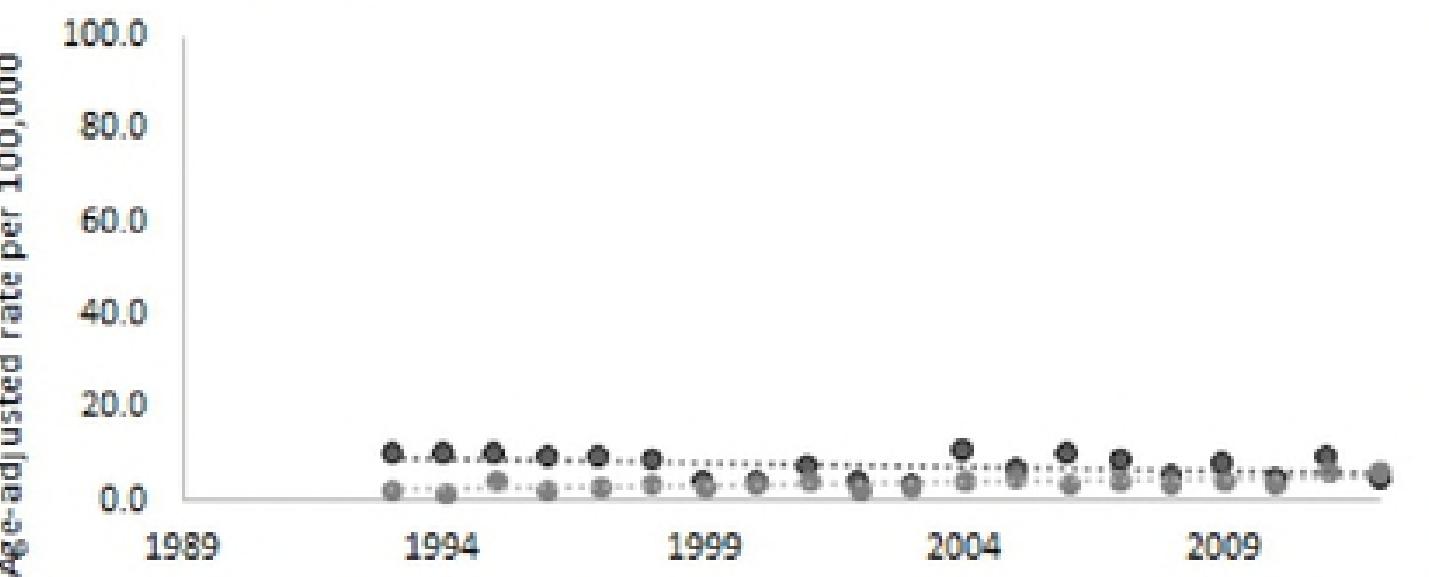

- Standardized incidence rate $60-74$ years …...... Incidence trend $60-74$ years

- Standardized incidence rate Total

Incidence trend Total

Male (Quito, Ecuador)

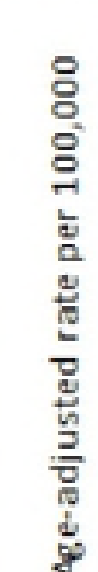

送

80.0

60.0

40.0

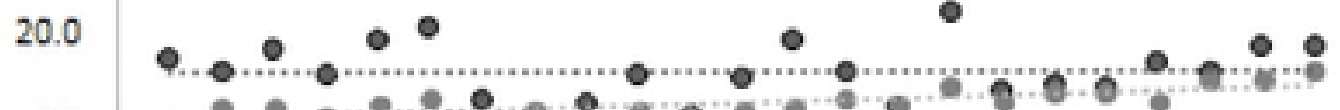
0.0

1989

1994

1999

20042009

- Standardized incidence rate 60-74 years

- Standardized incidence rate Total

Incidence trend $60-74$ years Male (Valdivia, Chile)

응

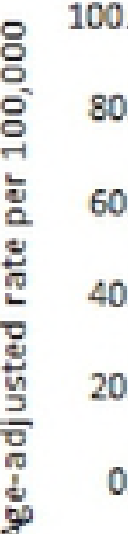

80.0

60.0

40.0

20.0
0.0

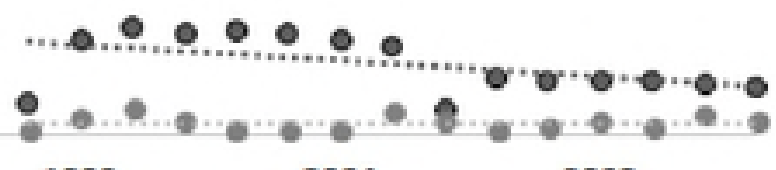

- Standardized incidence rate $60-74$ years

2004

2009
Female (Cali, Colombia)

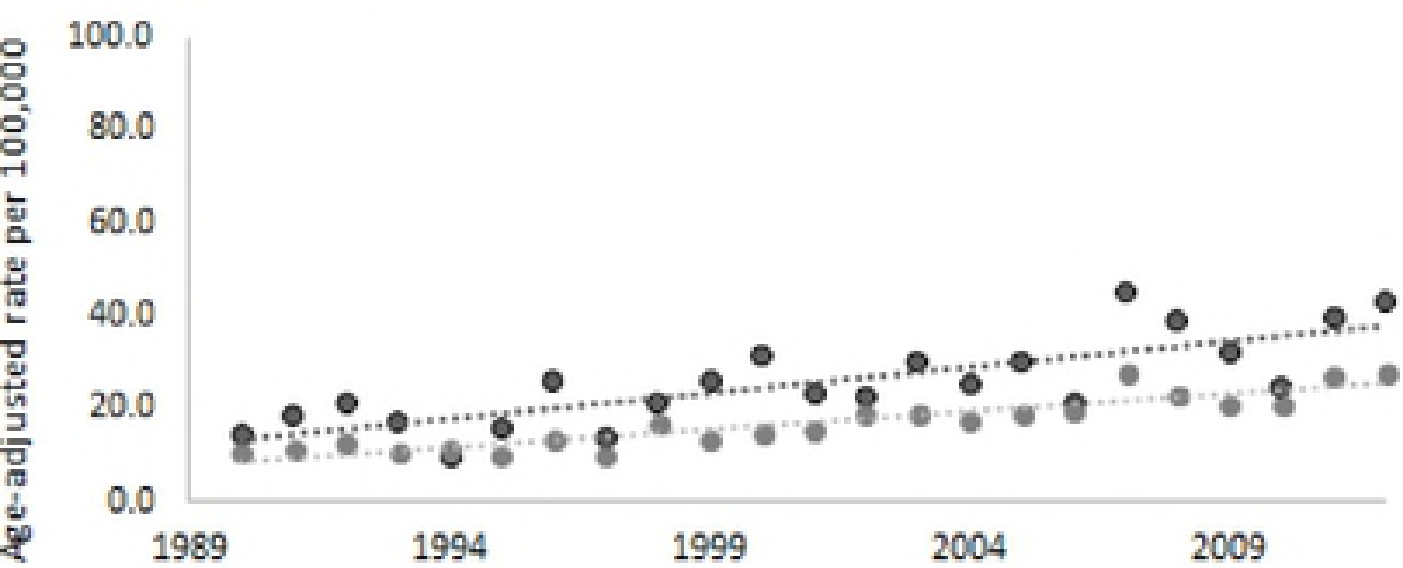

- Standardized incidence rate $60-74$ years

- Standardized incidence rate Total

Incidence trend 60-74 years Female (Costa Rica)

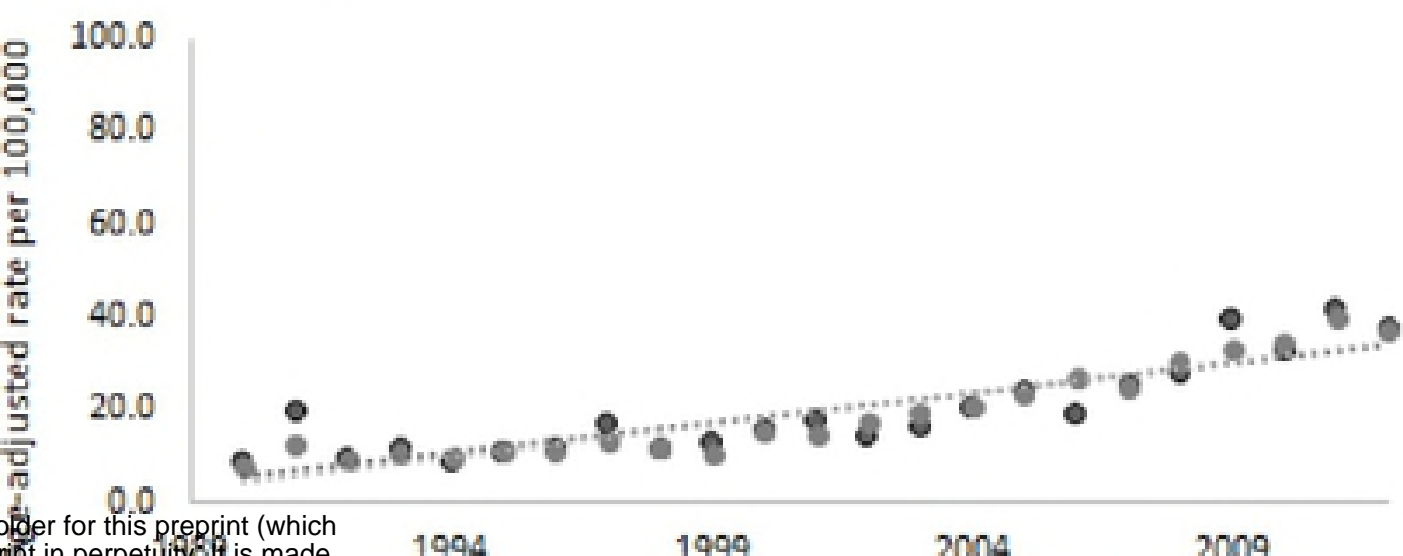

- Standardized incidence rate 60-74 years Incidence trend $60-74$ years

- Standardized incidence rate Total Incidence trend Total

Female (Goiania, Brazil)

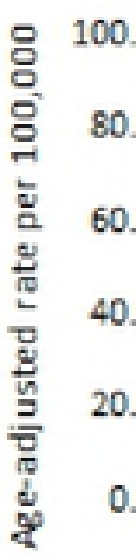

0.0
0.0
0.0
0.0
1989

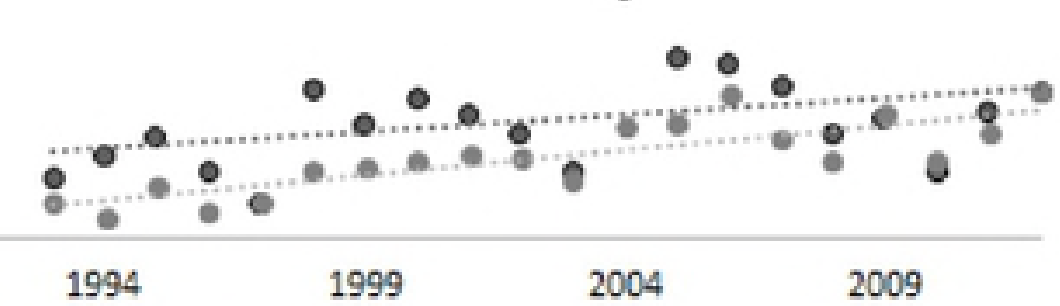

- Standardized incidence rate $60-74$ years

- Standardized incidence rate Total Incidence trend $60-74$ years Female (Quito, Ecuador)

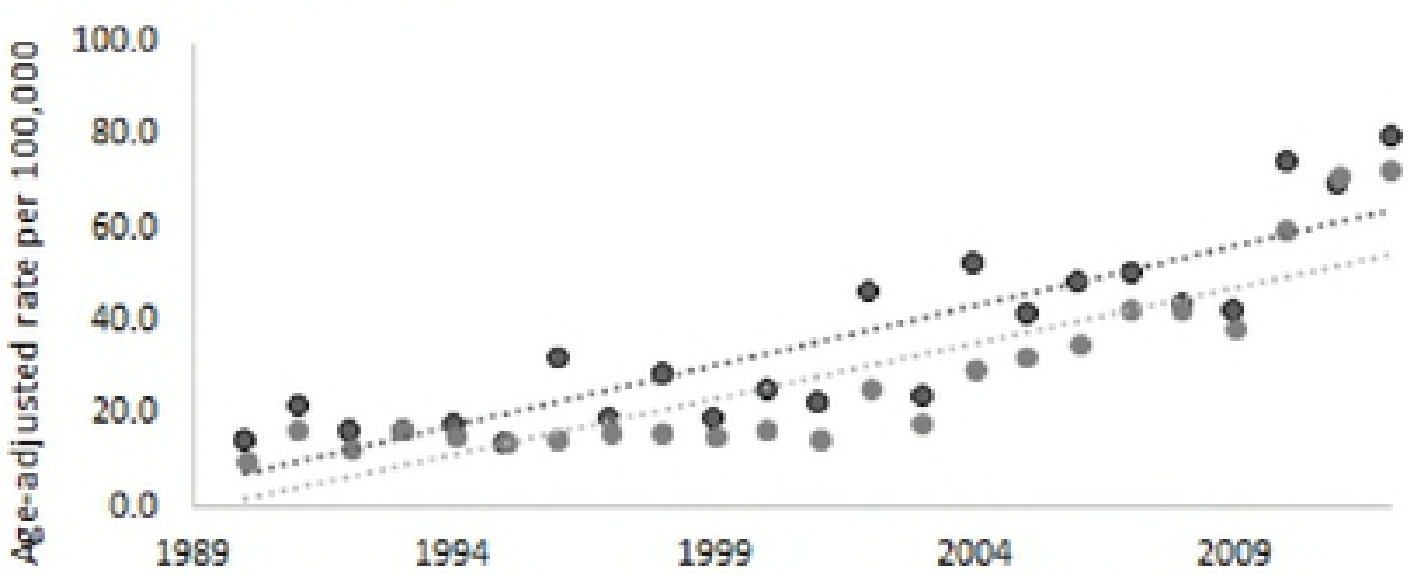

- Standardized incidence rate 60-74 years Incidence trend 60-74 years

- Standardized incidence rate Total Incidence trend Total

Female (Valdivia, Chile)

옹

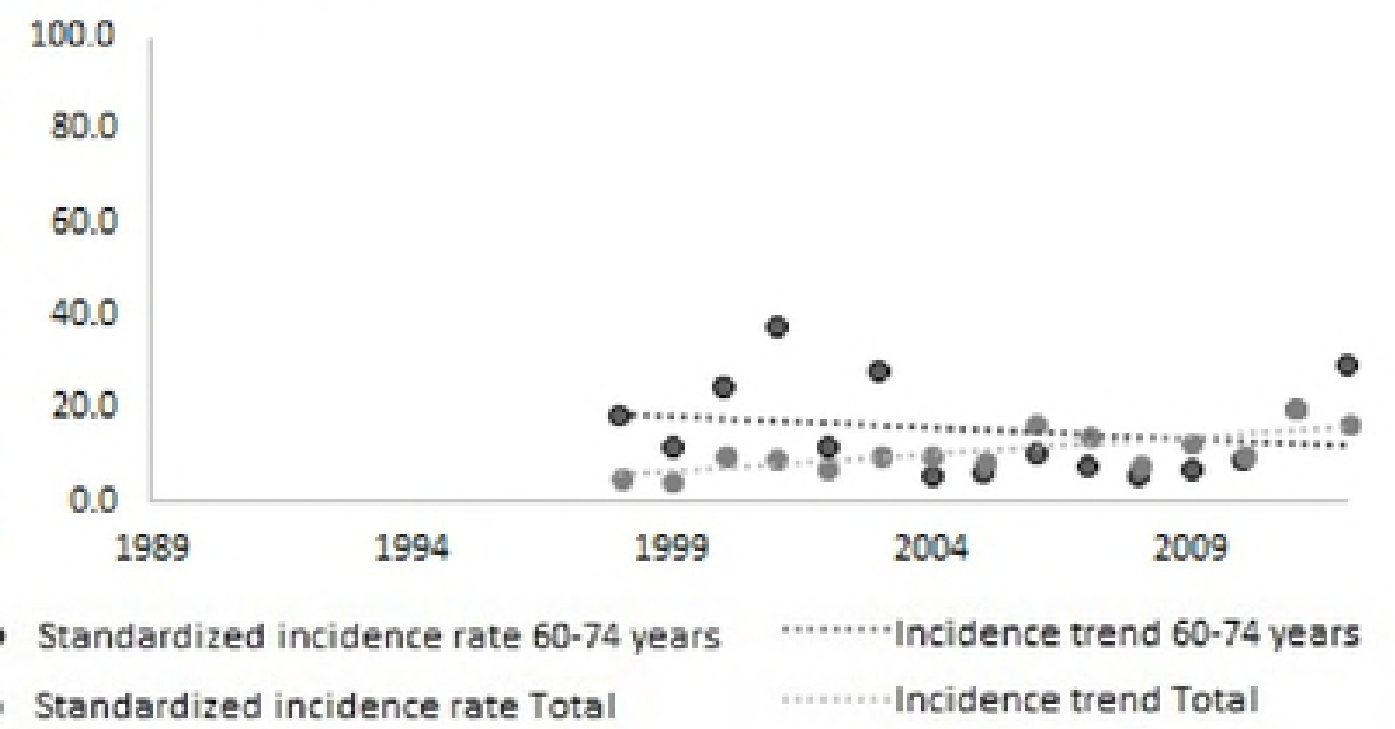

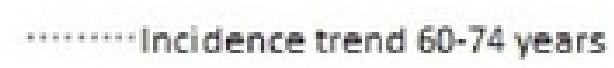
Incidence trend Total 
